\title{
stuos IBERO-AMERICANOS
}

\section{Vidas deslocadas pelo colonialismo e pela guerra Lives displaced by colonialism and war Vidas desplazadas por el colonialismo y la guerra}

Fátima da Cruz Rodrigues

Universidade de Coimbra. Coimbra, Portugal.

\begin{abstract}
Resumo
Quando uma guerra termina, não termina com ela tudo o que ela criou, modificou, violentou e destruiu. Depois de uma guerra, os que lhe sobrevivem têm de reconstruir-se e de recompor as suas vidas de acordo com esse legado em articulação com a realidade que o fim do conflito inaugura. Sobrevivem esses sobreviventes, e com eles as heranças que a guerra lhes deixou. É de algumas dessas heranças que trata este texto, que apresenta uma reflexão sobre a forma como a guerra colonial que Portugal travou em África entre 1961 e 1974 interferiu nos percursos de vida de antigos combatentes africanos que integraram as Forças Armadas Portuguesas (FAP) e que passaram a residir em Portugal, após a libertação dos territórios onde nasceram. Com base em um trabalho de pesquisa de caráter qualitativo com recurso a histórias de vida, procurou-se perceber o sentido que esses homens atribuíam aos seus percursos marcados por descontinuidades e momentos particularmente fraturantes no que toca a construção de projetos de vida. Para isso, caracterizam-se os diversos tipos de percursos que resultaram dessa análise, bem como alguns dos eixos discursivos que esses homens mobilizaram para justificar as diversas opções que tomaram ao longo dos mesmos. A análise é utilizada para interpelar a problemática da construção de identidades marcadas por descontinuidades e por posicionamentos aparentemente contraditórios ${ }^{1}$.
\end{abstract}

Palavras-chave: Pós-colonialismos. Guerras coloniais. Percursos de vida.

\begin{abstract}
When a war ends, it does not end with everything that is created, modified, violated, and destroyed. After a war, those who survive must rebuild and recompose their lives in accordance with this legacy in articulation with the reality that the end of the conflict inaugurates. These survivors survive and with them the legacies that the war left them. It is about some of these legacies that this text deals with a reflection on how the colonial war, that Portugal waged in Africa between 1961 and 1974 , interfered with the existence of former African combatants who were part of the Portuguese Armed Forces (PAF) and lived in Portugal after the liberation of the territories where they were born. Based on qualitative research with the use of life histories, the paths of some of these men were reconstructed and it was tried to understand the sense that they attributed to their existences marked by discontinuities and particularly fractured moments in the construction of life projects. This article characterizes the different types of paths that resulted from this analysis as well as some of the discursive axes that these men mobilized to justify the diverse options that they took along them. This analysis, in turn, is used to discuss the problem of the construction of identities marked by apparently contradictory positions.
\end{abstract}

Keywords: Post-colonialism. Colonial wars. Life paths.

\footnotetext{
Este artigo resulta, parcialmente, do trabalho desenvolvido no âmbito do projeto MEMOIRS - Filhos de Império e Pós-memórias Europeias, financiado pelo Conselho Europeu para a Investigação (ERC) no quadro do Horizonte 2020, programa para a investigação e inovação da União Europeia (contrato no 648624).

dados biográficos da autora_biographical data of the author
} 


\begin{abstract}
Resumen
Cuando una guerra termina, no termina con ella todo lo que ella creó, modificó, violó y destruyó. Después de una guerra, los que le sobreviven tienen que reconstruirse y de recomponer sus vidas de acuerdo con ese legado en articulación con la realidad que el fin del conflicto inaugura. Sobreviven estos sobrevivientes, y con ellos las herencias que la guerra les dejó. Es sobre algunos de estos legados que habla este texto que reflexiona sobre como la guerra colonial que Portugal protagonizó en África entre 1961 y 1974 interfirió en las de los antiguos combatientes africanos que han integrado las Fuerzas Armadas Portuguesas (FAP) y que pasaron a vivir en Portugal después de la liberación de los territorios donde nacieron. Con base en un trabajo de investigación de carácter cualitativo con recurso a historias de vida, se reconstruyeron las trayectorias de vida de algunos de esos hombres y se procuró percibir el sentido que los mismos atribuyeron a sus existencias marcadas por discontinuidades y momentos particularmente fracturantes en lo que toca a construcción de proyectos de vida. En este texto se caracterizan los diversos tipos de recorridos que resultaron de este análisis así como algunos de los ejes discursivos que esos hombres movilizaron para justificar las diversas opciones que tomaron a lo larrgo de los mismos. Esta análisis, a su vez, se utiliza para interpelar la problemática de la construcción de identidades marcadas por posicionamientos aparentemente contradictorios.

Palabras clave: Postcolonialisms. Guerras coloniales. Itinerarios de vida.
\end{abstract}

\section{Introdução}

Neste artigo apresenta-se uma análise relativa a percursos de vida de antigos combatentes africanos, residentes em Portugal, que integraram as Forças Armadas Portuguesas (FAP) ao longo da Guerra colonial portuguesa (1961-1974) que decorreu em Angola, em Moçambique e na Guiné-Bissau. Essa reflexão resulta de uma investigação que teve por objetivo compreender como esses homens interpretavam os seus percursos de vida a partir das narrativas biográficas ${ }^{2}$ de quarenta antigos combatentes africanos residentes em Portugal. Tal como defendem diversos autores, a interpretação das narrativas biográficas permitiu situar e interpretar os seus percursos em relação às condições materiais, aos lugares identitários e aos posicionamentos que eles foram ocupando ao longo dos diversos contextos sociais que os seus percursos de vida foram atravessando (LAKATOS; MARCONI, 1991, p. 107-112; GUERRA, 2006, p. 13-26; DEMAZIÈRE, 2011).

Reconhecendo que o conjunto de homens abrangidos nesta pesquisa, como na maioria das investigações qualitativas, não pode ser considerado estatisticamente representativo de universos culturais, sociais, políticos e ideológicos, seguiu-se o princípio da representatividade social segundo o qual se procura garantir uma diversidade máxima de perfis, de opiniões, de expectativas relativamente aos sujeitos a entrevistar e alcançar a saturação do material recolhido (GUERRA, 2006, p. 20-21). Além disso, defende-se, tal como Pàmpols (2006, p. 40), que através das narrativas biográficas

2 Sobre a especificidade deste tipo de entrevistas consultar Fritz Schutze (2011, p. 210-222), Sandra Jovchelovitch e Martin Bauer (2012, p.90-113), José M. Pais (2007, p. 147), e Uwe Flick (2005, p. 100-107). é possível aceder a pistas sobre a configuração de sistemas sociais dos quais as vidas narradas fazem parte. Para aumentar a possibilidade de encontrar essas pistas, adotou-se um estilo etnográfico que, além de recorrer à aplicação de entrevistas, utilizou a observação como uma das técnicas privilegiadas de recolha de dados por considerar que, "[...] permite uma análise global e intensiva do objecto de estudo" (ALMEIDA; PINTO, 1982, p. 97) ${ }^{3}$. Embora os relatos de vida e a observação tenham ocupado um lugar de destaque nessa pesquisa, não constituíram os únicos discursos analisados. Aplicaram-se entrevistas a muitos outros antigos combatentes não africanos e participou-se de diversos encontros e cerimônias de rememoração da guerra de modo a obter dados que permitissem entender a complexidade da problemática em causa. Além disso examinaram-se textos da imprensa portuguesa relativos ao período em que decorreu a Guerra, bem como uma diversidade de documentos de arquivos históricos. Esses registos serviram para recolher dados que informassem sobre o recrutamento de africanos nas FAP, as funções que desempenharam na guerra, e as representações desses combatentes veiculadas ao longo da época do conflito ${ }^{4}$. Apesar de esta recolha de dados ter sido efetuada entre

\footnotetext{
3 Utilizou-se uma observação parcialmente participante porque se, por um lado, ao longo da investigação fomos acompanhando e participando em várias atividades do quotidiano de antigos combatentes, inclusive na esfera privada das suas vidas, por outro lado, o investigador, neste caso concreto, nunca poderia integrar-se intensamente num grupo pelo simples fato de ser mulher, branca, europeia, e não ter vivido a guerra como um combatente.

4 Em relação à imprensa procurou-se, igualmente, dados que remetessem para as formas como estes combatentes eram caracterizados na época da Guerra. Quanto aos documentos recolhidos nos Arquivos Históricos, a saber o Arquivo Histórico-Diplomático do Ministério dos Negócios Estrangeiros (AHDMNE), o Arquivo Geral do Exército (AGE), o Arquivo Histórico-Militar (AHM) e
} 
os anos 2007 e 2011, considera-se que os resultados da pesquisa que apresentaremos permitem refletir sobre outros percursos e identidades relativos a outras realidades que não exclusivamente a da guerra colonial que Portugal travou na África. Isto porque espera-se que essa reflexão possa servir de referente analítico para compreender trajetórias e discursos de sujeitos cujas vidas são marcadas por deslocamentos geográficos derivados, sobretudo, de profundas transformações e de ruturas abruptas de contextos sociais e políticos, tal como sucede em qualquer cenário pós-guerra.

Para a interpretação dos dados respeitantes aos percursos de vida dos antigos combatentes, contamos com os métodos comparativo e tipológico. Através deles selecionaram-se similitudes e divergências, elementos constantes e gerais nas trajetórias individuais dos sujeitos e construiu-se uma tipologia com o objetivo de identificar trajetórias coletivas. Para que se percebam esses percursos de vida, este texto começa com alguns dados relativos ao recrutamento desses antigos combatentes africanos ao longo das guerras de independência de Angola, Moçambique e Guiné-Bissau e uma descrição sumária dos processos de desmobilização que ocorreram com o final desses conflitos e das situações em que esses homens se encontraram, nos seus países de origem, aquando das suas independências. O texto encerra com a análise dos diversos tipos de percursos identificados, acompanhados por alguns dos principais eixos discursivos que esses homens mobilizaram para justificar as diversas opções que tomaram ao longo dos mesmos. Conclui-se com uma proposta a partir da qual se sugere que a interpretação desses percursos permite interpelar a problemática da construção de identidades marcadas por descontinuidades e por posicionamentos múltiplos, ambíguos e aparentemente contraditórios.

\section{Recrutamento e desmobilização dos combatentes africanos das FAP em Angola, em Moçambique e na Guiné-Bissau}

Ao longo da guerra colonial que decorreu em Angola, em Moçambique e na Guiné-Bissau, Portugal

o Arquivo da Defesa Nacional (ADN), procurou-se compreender como eram integrados estes soldados nas FAP, conhecer os contornos das negociações da transferência de poderes, saber como foram ponderadas as desmobilizações destes combatentes e quais foram os principais problemas que foram colocados em relação a essas desmobilizações nos acordos entre as partes envolvidas. recrutou homens de origem africana para combaterem no seio das suas forças armadas. Entre 1961 e 1974 milhares de africanos lutaram contra as forças dos movimentos de libertação dos territórios africanos onde nasceram. Em termos globais, os dados disponíveis indicam que entre 1961 e 1973 aproximadamente um terço dos efetivos totais mobilizados para a Guerra fariam parte do recrutamento local, isto sem contar com as forças chamadas irregulares ou auxiliares ${ }^{5}$. Importa realçar que cada território apresentou especificidades quanto ao recrutamento local, quer no que respeita o tipo de forças envolvidas, quer quanto ao número de efetivos recrutados ao longo da Guerra $^{6}$. Na sua totalidade os efetivos do recrutamento local nunca atingiram os totais dos mobilizados em Portugal, contudo "[...] o recrutamento local cresceu continuamente mais do que duplicando entre 67 e 73 " (CORREIA, 2000, p. 145) ${ }^{7}$. No final dos conflitos, se incluirmos os Grupos Especiais, os Grupos Especiais de Paraquedistas, os Fiéis e os Flechas, as milícias, a Organização Provincial de Voluntários de Defesa Civil, e as Guardas Rurais, em termos totais o recrutamento local representava valores muito próximos dos $50 \%$ de efetivos presentes nos três territórios.

Com o fim das guerras e com os acordos que firmaram as independências de Angola, da Guiné-Bissau e de Moçambique, os africanos que se encontravam, na época, integrados nas FAP, foram desmobilizados. Essa desmobilização, bem como a posterior integração dos antigos combatentes nos novos Estados africanos, assumiu contornos diferentes conforme um conjunto de circunstâncias e de condições prevalecentes nos

\footnotetext{
5 Ver dados disponíveis em Portugal. Estado Maior do Exército (1988). Apesar da utilidade desta obra, sobretudo quanto aos dados que oferece, importa salientar, como chama a atenção Michel Cahen, para alguns problemas que suscita, tais como a presença de mitos relativos à legislação e à questão racial, a ausência de referências a insurreições e massacres, entre outros, o que revela, segundo o mesmo autor, que se trata de uma obra de "autolegitimação de toda a política colonial" (1991, p. 67).

6 Para conhecer as especificidades do recrutamento local em relação a cada território consulte-se, por exemplo, Correia (2000, p. 155) e Rodrigues (2017, p. 37-74).

Apesar desses valores, e segundo Pezarat Correia, sendo o total da população de Portugal $(8900000)$ inferior à dos três territórios (11980 000 valor subestimado) e sabendo que os efetivos da Marinha e da Força Aérea eram, sobretudo, do recrutamento português, então foi sobre os últimos que recaiu o maior peso do esforço de guerra. Perspectiva reforçada pelo fato de a maioria das unidades do recrutamento local estar sediada fora de zonas operacionais e o número de mortes dos efetivos locais também ter sido sempre inferior ao de Portugal, exceto na Guiné, onde não havia zonas não-operacionais e onde o número de soldados africanos mortos ultrapassou o de Portugal (2000, p. 146-147).
} 
três territórios, quer ao longo das guerras, quer nos primeiros anos das suas independências ${ }^{8}$.

No caso de Angola, a guerra civil que se instalou nesse território, decorrente das rivalidades que já se faziam sentir durante a Guerra Colonial entre o MPLA, a FNLA e a UNITA, terá constituído uma oportunidade para que esses antigos combatentes se integrassem "sem problemas" nesse novo contexto que inaugurava a Angola pós-colonial ${ }^{9}$, situação que contrastou com o que sucedeu em Moçambique e na GuinéBissau. Em relação a Moçambique, tudo indica que a implementação de uma política marxista-leninista foi responsável pela discriminação, pela exposição pública e pelo internamento de muitos desses homens nos chamados “campos de reeducação". Mas, à semelhança do que se sucedeu em Angola, a nova guerra que, entretanto, eclodiu em Moçambique, terá sido também ela responsável pela integração de antigos combatentes no seio das forças que entretanto se digladiaram ${ }^{10}$. $\mathrm{Na}$ Guiné-Bissau, o papel que foi atribuído a esses combatentes durante a Guerra Colonial, sobretudo nos seus últimos anos, constituiu um dos fatores responsáveis pelo desenrolar dos episódios conturbados da sua desmobilização bem como das perseguições, detenções e execuções de alguns desses homens que se verificaram nos primeiros anos da Guiné independente (RODRIGUES, 2017, p. 75-112) ${ }^{11}$.

Perante as dificuldades que defrontam nos seus países de origem, alguns antigos combatentes africanos das FAP partem para Portugal à procura de oportunidades para refazerem as suas vidas. E são os percursos desses homens que, depois das guerras vão residir para Portugal, que procuramos perceber nesta

\footnotetext{
8 Sobre os fatores que influenciaram as desmobilizações dos africanos das FAP nos três territórios, bem como a sua posterior integração nos novos Estados independentes, consulte-se Rodrigues (2013, p. 113-128; 2017, p. 75-112).

9 Para conhecer pormenores relativos à desmobilização dos combatentes africanos em Angola, a forma como foi discutido este processo nas reuniões do Acordo de Alvor e a integração desses homens no seio das forças dos três movimentos indicados consulte-se Fátima Rodrigues (2013, p. 160-166), Joseph Cervelló (1998, p. 89-98). Coelho (2003, p.192-193), Leão e Rupiya (2005) e o Acordo de Alvor (AHDMNE, 1316-PAA, p. 944). entre outros. ${ }^{10}$ Sobre a desmobilização dos antigos combatentes africanos das FAP em Moçambique e a sua detenção em centros de reeducação consulte-se, por exemplo, Elias Jossias (2007, p. 24-46), o Acordo de Lusaca, Manuel Bernardo (2003, p. 257-269), António Coelho (2003, p. 190-191; 2002, p. 150) e Fátima Rodrigues (2013, p. 167-174).

${ }^{11}$ Para conhecer alguns pormenores que envolveram as desmobilizações, as detenções e execuções dos antigos combatentes africanos na Guiné-Bissau consulte-se o Acordo de Alvor, Amaro Bernardo (2007, p. 160), Rui Rodrigues (1995, p. 191-192) e Luíz Aguiar (1977, p. 467-468), entre outros.
}

pesquisa o que, tendo em conta as suas particularidades, obrigou a recorrer a abordagens teóricas que conseguissem captar o significado de trajetórias marcadas por descontinuidades e por posicionamentos e deslocamentos identitários múltiplos (RODRIGUES, 2017, p. 75-112).

\section{Enquadramento teórico: uma breve síntese}

De maneira a perceber como os percursos desses homens foram afetados pela guerra, pelo colonialismo e pelas realidades pós-coloniais que atravessaram, socorremo-nos de uma abordagem interpretativa que servisse de referência para compreender trajetórias de vida que foram acontecendo no cruzamento de circunstâncias e de narrativas históricas, sociais e pessoais múltiplas. Isto porque os percursos desses homens atravessaram diversos contextos, no seio dos quais assumiram diversos posicionamentos. Além da guerra, os seus percursos devem ser lidos tendo em conta um outro contexto mais amplo que abrange o tempo da colonização portuguesa na África e dos espaços-tempo que a substituíram. Temporalidades distintas que marcaram profundamente, mas também de modo diferenciado, as estruturas econômicas, sociais, culturais e políticas de Portugal, de Angola, de Moçambique e da Guiné-Bissau coloniais e póscoloniais. Realidades que, embora distintas, são indissociáveis entre si, porque os novos contextos, inaugurados com o 25 de Abril e com as independências dos territórios africanos, não se configuraram sem trazer em si heranças daqueles tempos da guerra e do colonialismo.

São essas considerações que pressionaram esse estudo em direção a propostas epistemológicas capazes de dar conta das múltiplas vozes que se entrecruzam nas diversas temporalidades de enunciação e de circunstâncias em que os percursos desses homens foram acontecendo e foram contados. Nesse sentido convocaram-se abordagens especialmente atentas ao caráter ambíguo e ambivalente que caracteriza as relações e os sujeitos coloniais e póscoloniais (BHABHA, 2005a, 2005b; PRATT, 1991; MALDONADO-TORRES, 2007; SAID， 1995; SANTOS 2004) e a construção de identidades que interpelam posicionamentos dicotômicos (COLLINS, 2000; FRIEDMAN, 2001; HALL, 1997, 2006; HOOKS, 2004, SPIVAK, 1988). Porque é precisamente este o sentido em direção ao qual os percursos desses antigos 
combatentes encaminharam esta análise. Na época das guerras, esses homens, africanos, foram chamados a combater no seio da força militar colonial contra as forças dos movimentos que lutavam por libertar os territórios onde nasceram do domínio colonial. Durante a guerra, esses combatentes ocuparam, temporariamente, um lugar do colonizador o qual passou a ser um posicionamento que comprometeu as suas vidas quando os territórios africanos, onde nasceram, se tornaram independentes.

Esses são lugares múltiplos, aparentemente conflituais e contraditórios, que se sobrepõem no decorrer de certos momentos das suas vidas, e que remetem, antes de mais, para a problemática da relação colonial, mais precisamente para a relação entre colonizado e colonizador, e para a possibilidade de o primeiro ocupar o lugar do segundo. Para compreender essa relação recorreu-se a perspectivas que permitissem equacionar o colonialismo como um processo de dominação não unívoco e que sugerem que a relação colonial, inquestionavelmente desigualitária, é também um território de negociação, de implicação, de resistência, de desestabilização e de tradução. Propostas onde as fronteiras que separam Uns dos Outros são interpretadas como lugares de encontro, "zonas de contato" (PRATT, 1992), "entre-lugares" (BHABHA, 2005a), onde acontecem dinâmicas transculturais geradoras de mútuas crioulizações identitárias, construídas nas tensões e nos conflitos do encontro colonial e pós-colonial. Recorrer à crítica pós-colonial, e a outras abordagens que exploram a ambiguidade das relações e identidades sociais, contribuiu para que a análise dos percursos desses homens fosse construída a partir de um olhar que permitisse problematizar os múltiplos posicionamentos ao longo dos quais os antigos combatentes foram imaginando e tecendo as suas vidas.

\section{Da heterogeneidade dos Antigos Combatentes Africanos à tipologia dos seus percursos de vida}

Os percursos dos antigos combatentes africanos das FAP atravessaram condicionalismos que afetaram profundamente e por diversas vezes os rumos que seguiam as suas vidas. Nascidos na África sob o colonialismo português, a guerra chamou-os a combater do lado da força colonial. Essa passagem pela guerra, que indelevelmente marcou todos os que a experienciaram, tornou-se particularmente determinante quanto ao que o futuro lhes reservava.
Apesar de todos terem passado mais ou menos pelas mesmas rupturas e descontinuidades geradas pelas profundas transformações históricas que atravessaram as suas vidas, os percursos desses homens não foram todos afetados da mesma forma. Até porque os antigos combatentes africanos são um grupo muito heterogéneo. O território onde nasceram, as suas crenças religiosas, línguas, contextos socioculturais, níveis de instrução e condições econômicas, bem como o serviço militar obrigatório que cumpriram nas mais variadas unidades e especialidades militares constituem alguns dos aspectos que os diferenciam entre si.

Apesar dessa heterogeneidade, com base na comparação de vários fatores relativos aos seus percursos de vida e aos significados que lhes atribuíam, as suas trajetórias manifestaram certos padrões a partir dos quais foi possível propor uma tipologia composta por seis percursos-tipo: percursos-tipo ancorados, deambulantes, indecisos, suspensos, pendentes e radicados à força. Esses percursos-tipo distribuem-se ao longo de um eixo cujos extremos correspondem a dois percursos-tipo opostos. De um lado o percurso dos antigos combatentes ancorados, que correspondem aos homens que em Portugal encontraram o lugar onde sentem que realizaram os seus projetos de vida. Do outro lado, o percurso-tipo deambulante, que reúne aqueles que ainda andavam à procura de um lugar onde sentissem que pudessem pertencer. Entre esses dois percursos-tipo, opostos entre si, identificamos outras quatro trajetórias: os percursos-tipo indecisos em Portugal, que dizem respeito aos homens que tinham as suas vidas organizadas em Portugal, mas que estavam indecisos quanto à possibilidade de ficarem ou partirem para outros territórios; os percursos suspensos que reúnem os homens que vieram para Portugal temporariamente, mas cuja estadia se prolongou por tantos anos que significou a interrupção dos seus projetos de vida por tempo indeterminado; os percursos pendentes que são os dos homens que aguardavam a resolução dos seus processos de reforma antes de decidirem o que fariam depois; e os percursos de homens radicados em Portugal à força porque desejavam regressar às suas terras natais sem, contudo, terem condições para o fazerem. Como qualquer tipologia, a que acabamos de expor não é capaz de dar conta da diversidade e complexidade dos percursos que pretende classificar, mas a sua construção e utilização tornaram-se fundamentais para avançar para a compreensão não só desses mesmos percursos, como também dos discursos que os acompanham, os justificam ou os representam. 


\section{Percursos de vida desviados pela guerra}

Os percursos de todos os homens, europeus ou africanos, que participaram da guerra foram inquestionavelmente interrompidos. Em muitos casos, tratou-se de uma interrupção temporária de projetos de vida que foram, por alguns anos, adiados e posteriormente retomados e eventualmente reorientados após terem cumprido o serviço militar obrigatório. Para outros, os seus percursos não foram apenas interrompidos; foram desviados. No caso dos antigos combatentes africanos, para muitos deles, o fim da guerra e a independência e evolução dos novos Estados africanos, onde nasceram, traduziram-se na impossibilidade de retomarem ou de continuarem projetos anteriormente iniciados ou idealizados. Terem sido antigos combatentes das FAP constituiu o motivo pelo qual alguns deles foram perseguidos, aprisionados, "reeducados", excluídos, discriminados e até mesmo fuzilados pelas novas forças que ditavam o caminho da África independente ${ }^{12}$. Por isso, também alguns se sentiram forçados a deixar os seus territórios de origem. Mas, se estas situações se traduziram em uma série de impossibilidades quanto aos seus projetos nas suas terras natais, ser antigo combatente das FAP constituiu, ao mesmo tempo, um território de outras possibilidades concretizáveis ou não. Possibilidade de partir para Portugal, de conseguir uma reforma pelas FAP, de ter melhores condições de vida, de adquirir, para si e para a sua família, a nacionalidade portuguesa e de poder trabalhar em Portugal ou em qualquer país da Europa Schengen. Em suma, um território de possibilidades aberto pela sua participação nas FAP durante a guerra, e que esperavam e desejavam encontrar no Portugal pós-colonial que imaginavam.

É entre esses territórios múltiplos que os seus percursos se deslocam. É também entre esses territórios que os seus discursos identitários vão deslizando denunciando, não raras vezes, sobreposições e contaminações entre eles, mas também resistências e persistências contra hipóteses de dissolução de especificidades culturais. Percursos de vida que se diferenciam em função das suas trajetórias, do que deixaram nos seus países de origem, do que encontraram em Portugal, do que conseguiram reconstruir neste país

\footnotetext{
${ }^{12}$ Sobre a forma como as especificidades do envolvimento desses homens na guerra, dos seus processos de desmobilização das FAP e dos contextos dos novos Estados africanos influenciaram a situação em que ficaram com as independencias da Guiné-Bissau, de Moçambique e de Angola consulte-se Fátima Rodrigues (2017, p. 75-111).
}

e dos projetos que perspectivavam para o seu futuro. De acordo com estas coordenadas analíticas, os percursos de vida desses homens foram distribuídos pela tipologia de trajetórias composta pelos seis percursos-tipo atrás enunciados: ancorados; radicados à força; indecisos; pendentes; suspensos e deambulantes.

Em relação à trajetória-tipo ancorada, essa compreende os antigos combatentes africanos que consideram que conseguiram reorganizar satisfatoriamente as suas vidas em Portugal e que não conseguiam imaginar o seu futuro noutro lugar. Mas, nem todos interpretavam e justificavam esses percursos da mesma maneira, porque nem todos foram marcados da mesma forma pela guerra, pela colonização e pelos espaços-tempo que as substituíram. É o caso de Custódio, um homem ancorado a Portugal, mas cujo percurso foi desviado à força, pela força de um colonialismo que o arrancou da sua terra para onde nunca mais pôde regressar e que, ao mesmo tempo, contaminou o seu discurso. O seu percurso não denuncia ter sido profundamente marcado pela sua participação na guerra. O seu discurso também não. É a sua condição subalterna na relação colonial que desviou a sua vida para Portugal. É também essa condição que o fez oferecer-se voluntariamente para ir para à guerra. Ainda criança, Custódio trabalhava para um casal de portugueses radicado na Guiné. Quando começou a guerra, esse casal partiu para Portugal e Custódio foi com eles. Tinha, então, quinze anos e queria acompanhar os seus "patrões" porque pensava que iam, apenas, passar umas férias e logo regressariam à Guiné. Para poder fazer essa viagem, Custódio teve que declarar às autoridades que não tinha família para que os seus "patrões" pudessem tomá-lo a seu cargo. Depois de uma curta estadia em Portugal, o casal voltou para África, mas não para a Guiné e Custódio ficou com a mãe do "patrão" a tratar da sua quinta no Porto.

Passados uns anos, Custódio decide estudar, mas foi impedido de o fazer porque a família para quem trabalhava dizia que não tinha em sua posse os seus documentos. Depois de várias tentativas falhadas, a solução que encontrou, para obter os seus documentos, foi oferecer-se para ir para à guerra, decisão tomada contra a vontade da família que o "acolhia". Os seus documentos acabaram por aparecer no dia em que o chamaram à inspeção. Disseram-lhe que estavam "perdidos lá por casa". Assim, Custódio foi voluntariamente para a guerra, mas não para a sua terra natal. Foi mobilizado para Angola onde combateu entre 1970 e 1972. Quando a sua comissão terminou, voltou a trabalhar para a família do Porto até se casar. Assim, a 
sua estadia em Portugal acabou por tornar-se definitiva. Custódio nunca mais voltou à Guiné e pretendia passar o resto dos seus dias em Portugal, apesar de viver com muitas dificuldades econômicas. A única mágoa que dizia sentir era não ter voltado a ver sua mãe, que faleceu sem nunca ter voltado a vê-lo. Custódio dizia que não conhecia a Guiné, que não se lembrava da Guiné e que nem sequer sabia falar crioulo, mas não o lamentava. Custódio optou pela nacionalidade portuguesa em 1977 e considerava-se exclusivamente português, embora de vez em quando o seu discurso deslizasse para as suas raízes: "tenho raízes lá, aqui não tenho. Aqui tenho amigos e tenho a pátria. Fiquei porque quis". Apesar de o seu percurso de vida ter sido desviado para Portugal definitivamente por uma família de colonos portugueses, Custódio sentia que este era o seu território de pertença ${ }^{13}$.

O percurso de Alberto de Moçambique também corresponde à trajetória-tipo ancorada. Tal como Custódio, Alberto não conseguia imaginar a sua vida a não ser em Portugal, mas os motivos que desviaram o seu percurso foram outros: a guerra e as suas sequelas irreversíveis. Antes de ir para a guerra, trabalhava em uma empresa açucareira de África, era baterista de um conjunto musical e gostava de jogar futebol. Confessou que, na época, cumprir o serviço militar obrigatório era uma etapa da vida de um homem encarada com normalidade e considerada necessária para construir um futuro mais estável. Em setembro de 1969 foi chamado para cumprir o serviço militar e foi combater na zona de Cabo Delgado em uma companhia de comandos. Alberto esteve pela primeira vez em Portugal em 1970 por ter sido evacuado após ter sido vítima de uma mina que o deixou biamputado. Passados dois anos, depois de alguns meses de tratamentos e de reabilitação no Hospital Militar em Lisboa, regressou a Moçambique. Mas, o fim da guerra e a independência de Moçambique forçaram Alberto a tomar a decisão de deixar a sua terra natal. As marcas que a guerra deixou no seu corpo eram demasiado visíveis para serem indiferentes aos olhares que Moçambique lançava às incômodas heranças coloniais. Marcas que delatavam a sua participação na guerra e que condicionaram as decisões determinantes que Alberto tomaria quanto ao seu percurso.

[...] na altura tentei trabalhar na Beira, já depois do 25 de Abril, não consegui. [...] porque formaram-se logo grupos dinamizadores, depois

${ }^{13}$ Os depoimentos verbais de Custódio foram concedidos à autora em entrevista no Porto, no dia 6 de abril de 2011. da independência, $[. .$.$] em que eram todos naturais$ de lá, eram todos negros, a maior parte. E então como sabiam da origem do meu acidente, na guerra e foi dos comandos ainda por cima, agravou mais as coisas, então não tive emprego. [...] Aliás havia listas, uns quadros que punham em certos sítios públicos, [...] listas de pessoas que foram dos comandos. Atenção. Estava lá o meu nome também. Era público para as pessoas verem quem era dos comandos, para estar debaixo de olho (ALBERTO, informação verbal) ${ }^{14}$.

Apesar de o desfecho da sua participação na guerra o ter, assim, obrigado a desviar o seu percurso para Portugal, Alberto não mostrava qualquer tipo de ressentimento ou rancor em relação ao seu envolvimento nesse conflito. Pelo contrário, Alberto aceitava a sua condição e considerava-se satisfeito com os apoios que encontrou em Portugal.

Porque é que se vai chorar sobre leite derramado? [...] Se calhar lamentar-me-ia era, por exemplo, se o Estado tivesse-me abandonado! Por exemplo, tive este acidente, se dissesse 'olha escolhe um canto aí e vai pedir esmola', aí sim, mas não. [...] Tenho dificuldades na prótese, dão prótese nova, se tem avaria arranjam-me as próteses. Tenho uma pensão que não morro à fome, tenho a família, deu para eles estudarem e os meus filhos, estão mais ou menos encaminhados. É claro que eu gostaria de correr, gostava de correr mas não posso. Coisas assim do género. Agora chorar, 'ai a guerra'. Sempre houve guerras e vai sempre havendo [...] (ALBERTO, informação verbal $)^{15}$.

Alberto e Custódio, bem como muitos outros, eram homens cujos percursos se situavam na trajetória-tipo ancorada ${ }^{16}$. Todos os outros percursos-tipo distanciamse, mais ou menos, desse polo. Ainda muito próximos das trajetórias de tipo ancorado encontravam-se os percursos de Amadú e de Emanuel. Distinguem-se daqueles fundamentalmente porque projetavam o futuro da sua vida quer em Portugal, quer nas suas terras natais. São homens que estavam radicados em

\footnotetext{
${ }^{14}$ Depoimento verbal de Alberto concedido à autora em entrevista em Lisboa, no dia 14 de janeiro de 2008.

${ }^{15}$ Depoimento verbal de Alberto concedido à autora em entrevista em Lisboa, no dia 14 de janeiro de 2008.

${ }^{16}$ Bacar, Hilário, Luís, Octávio, Rolando, Cassamá, naturais da Guiné; Ari, Chico, Henrique, Daniel e Fernando naturais de Moçambique; André e Jorge naturais de Angola são os restantes antigos combatentes situados nessa trajectória-tipo ancorada.
} 
Portugal, mas que estavam indecisos quanto ao lugar onde imaginavam passar o resto das suas vidas.

A vida de Emanuel corresponde a esse percurso. Ele mostrava-se indeciso entre percursos de vida possíveis em dois planos distintos. Um em Portugal, onde voltou a encontrar parte do rumo do qual a sua vida foi desviada pelo desfecho da sua participação na guerra, o outro em Moçambique onde imaginava a possibilidade de poder vir a reencontrar o que um dia lá tinha deixado. $\mathrm{O}$ seu percurso foi profundamente marcado pela sua passagem pela guerra. Como aconteceu com o Alberto, a guerra deixou no seu corpo marcas profundas. Mas Emanuel tinha menos autonomia do que o Alberto; vivia dependente de uma cadeira de rodas. Não se queixava da sua condição e era precisamente essa, segundo ele, que o tornava português. Nas suas palavras

Ser português, é primeiro uma pessoa quando está num país como este tem que estar aqui oficialmente, a seguir para beneficiar de alguns direitos que um cidadão comum beneficia, tem que ter a nacionalidade portuguesa, porque sem nacionalidade portuguesa não posso beneficiar em nada. Os deveres, já cumpri [...], estou assim porque estava a cumprir o meu dever como cidadão português. [...] Já cumpri (EMANUEL, informação verbal) ${ }^{17}$.

O que Emanuel lamentava, na realidade, era ter visto o seu desejo de estudar interrompido quando foi recrutado à força para a tropa. Emanuel queria frequentar o seminário mas, para se matricular, tinha que ter o bilhete de identidade; para tê-lo foi ao administrador e este, segundo Emanuel, chamou uns soldados que verificaram que estava apto para ser recrutado. Pouco tempo depois, foi chamado para o serviço militar. Emanuel gostaria de ter voltado para Moçambique quando acabasse os estudos que retomou desde que residia em Portugal ${ }^{18}$. Queria voltar para rever a sua mãe. Mas também queria voltar reformado como DFA porque dizia que, assim, poderia recuperar o que o serviço militar lhe tinha tirado. Ao mesmo tempo, Emanuel reconhecia que nunca, nem nada poderia restituir o sonho de ser padre que viu escapar quando foi cumprir o serviço militar. Enquanto aguardava, Emanuel vivia em um lar do Estado português para

\footnotetext{
${ }_{17}$ Depoimento verbal de Emanuel concedido à autora em entrevista em Lisboa, no dia 19 de fevereiro de 2008.

${ }^{18}$ Emanuel chegou a Portugal no ano de 2004.
}

onde foi transferido após ter estado em um quartel que não oferecia condições adequadas às suas necessidades especiais. Entretanto, o seu percurso, desviado pela guerra, foi retomado em Portugal. Emanuel voltou a estudar e ambicionava frequentar o Ensino Superior. Deste modo, Emanuel acabou por encontrar em Portugal parte do rumo do qual foi desviado quando foi cumprir o serviço militar. Radicado, mas indeciso entre ficar em Portugal e regressar para Moçambique, Emanuel ia alimentando e imaginando um projeto de vida em dois planos distintos.

A vida de Amadú também se apresentava como situada na trajetória-tipo indecisa. Radicado em Portugal, mas por motivos bem diferentes dos de Emanuel, Amadú também ia imaginando a sua vida entre Portugal e a sua terra natal. Era em Portugal que dizia ter realizado grande parte dos seus desejos. Apesar disso ponderava regressar à Guiné-Bissau. Isto porque, lá dizia ter deixado as suas esposas e as suas propriedades, e um clima que era favorável a sua saúde debilitada, mas também era na Guiné que sentia que o seu passado, na época colonial, ainda o comprometia e lhe podia trazer problemas e, por isso, preferia ficar em Portugal.

Amadú foi oficial graduado do Exército português, em uma companhia de comandos africanos na Guiné, e combateu durante onze anos nesse território. Entrou para o serviço militar em 1962, ainda a guerra não tinha "oficialmente" começado na Guiné e permaneceu nas FAP até ao dia 1 de Janeiro de 1975. Com a independência da Guiné, Amadú escapou várias vezes à prisão e conseguiu partir para Portugal, pelos seus próprios meios, e concluir o processo que o considerou membro das FAP. Para poder usufruir da cidadania portuguesa, e obter a reforma pelas FAP, Amadú foi obrigado a requerer a nacionalidade portuguesa que perdera com a independência da Guiné. As práticas quotidianas de Amadú representavam, em muitas ocasiões, a multiplicidade que caracteriza as identidades desses antigos combatentes derivadas de percursos de vida apanhados por circunstâncias históricas contraditórias nas quais as suas vidas foram enredadas. Ocasiões que não revelavam, apenas, as múltiplas pertenças dos antigos combatentes africanos, mas também um percurso de vida que, desviado pela guerra, encontrava, em certos momentos, como as cerimónias de rememoração da guerra às quais assistia sempre que podia, um lugar onde sentia pertencer.

Amadú sempre se mostrou hesitante quanto ao lugar onde queria continuar a viver a sua vida. Por vezes, queria regressar à Guiné, onde situava e projetava 
o seu futuro. Decisão que ia adiando à medida que ia realizando vários projetos que queria concretizar antes de partir. Outras vezes só desejava partir porque considerava que o clima português prejudicava a sua saúde, e queria morrer e ser sepultado na sua terra natal. Ao mesmo tempo, ia, contudo, construindo outros projetos que só podiam ser concretizados em Portugal. Assim ia imaginando o seu futuro entre Portugal e a Guiné simultaneamente.

Amadú faleceu em Portugal mas o seu corpo foi transferido para a Guiné onde desejava ser sepultado ${ }^{19}$. O percurso de vida de Amadú não foi deambulante, nem ancorado. Foi antes um percurso fora do seu lugar. Não foi apenas um percurso desviado pela guerra e deslocado para Portugal, foi um percurso e uma vida que tiveram dificuldade em encontrar um lugar onde podiam conciliar-se. Talvez por isso, o Amadú estava sempre indeciso em relação ao lugar onde queria continuar a viver, e por isso o colocamos nessa trajetória-tipo.

Outra trajetória que reúne bastantes antigos combatentes é a dos percursos pendentes. Esses homens residiam em Portugal há mais ou menos anos, e apresentavam a particularidade de aguardarem a resolução dos seus processos de reforma para decidirem o que fazer depois. Trata-se de percursos de vida interrompidos, dependentes daquela resolução cujo desfecho lhes podia ser, ou não, favorável e que podia demorar vários anos. Entretanto, esses homens iam sobrevivendo em Portugal com a ajuda de instituições ou com os trabalhos precários que iam arranjando. Enquanto esperavam pela resolução dos seus processos, o tempo passava. O João da Guiné apresenta uma trajetória de vida desse tipo. O João esteve envolvido nas FAP durante seis anos. Antes da guerra, trabalhava em uma empresa portuguesa, a Casa Ultramarina em Bissau, com um tio que lá era motorista de caminhões. Nascido em Bula, o João foi viver em Bissau para poder fazer a 4a classe e aprender um ofício. Terminou a 4a classe em 1963, ano em que foi recenseado e, passados dois anos, foi chamado a cumprir o serviço militar. Depois da sua passagem pela guerra, como tinha carta de condução profissional que tirara no seu serviço militar, começou a trabalhar como motorista e com a independência passou a trabalhar para o governo da Guiné Bissau. Mas o João adoeceu e foi evacuado para Portugal, em 1986, para fazer

\footnotetext{
${ }^{19}$ Outros antigos combatentes foram falecendo desde que se recolheram os dados que serviram esta análise. Dada a impossibilidade de atualizar constantemente estes dados optou-se por apenas se fazer esta referência ao falecimento de Amadú.
}

tratamentos. Durante essa primeira estadia, a sua mãe faleceu na Guiné, e ele só regressou à sua terra natal em abril de 1992. Decorridos dois anos voltou a Portugal e, quando o entrevistamos, ele admitia que só ia decidir o rumo a dar ao seu percurso quando o seu processo estivesse resolvido. Sempre que podia, o João ia à Guiné. Em 2007, onze anos após a sua primeira estadia em Portugal, João obteve a nacionalidade portuguesa e foi-lhe atribuída uma pensão de invalidez de duzentos euros por mês. Dizia que não tinha condições para reunir a sua família em Portugal. Afirmava que o seu maior desejo era dar uma oportunidade aos seus oito filhos de continuarem os estudos, sobretudo a um deles, que tinha o $12^{\circ}$ ano e não tinha trabalho, nem possibilidades para entrar na Universidade em Bissau. Por isso, também, ponderava regressar para a Guiné, exceto se conseguisse uma pensão como DFA. João dizia estar à espera pelo desfecho desse processo e que só depois decidiria se voltaria ou não para a Guiné.

$\mathrm{O}$ que distingue o percurso-tipo pendente que o João representa, dos percursos suspensos prende-se ao fato de os homens situados nos segundos saberem o que pretendiam fazer quando fossem criadas as condições para que os seus rumos de vida voltassem ao lugar de onde foram desviados, e por estarem em Portugal ao abrigo do seu "estatuto" de antigo combatente das FAP. As trajetórias de tipo suspenso correspondem aos percursos dos homens que partiram para Portugal, temporariamente, para requererem ou atualizarem as suas reformas de DFA, mas cuja estadia se prolongou durante tantos anos que os seus projetos de vida foram interrompidos por um tempo indeterminado. Esse é o percurso-tipo dos homens que residiam, temporariamente, em quartéis do exército português, mas que planejavam regressar às suas terras-natais logo que os seus processos de reformas fossem resolvidos ${ }^{20}$.

Por último, resta fazer uma referência aos percursos de tipo deambulante e de tipo ancorado à força. A esse último tipo corresponde a situação de José em Portugal. Trata-se de um homem que não encontrava em Portugal o que procurava, que não estava satisfeito com a sua vida neste país, que se mostrava descontente quanto à forma como o seu processo estava a ser tratado e que não percebia as razões pelas quais se encontrava nessa situação. Por todos estes motivos, José desejava voltar para Angola, mas estava radicado à força a Portugal uma vez que não tinha condições econômicas para regressar à sua terra natal.

\footnotetext{
${ }^{20}$ Sobre a forma como estes homens são recebidos em Portugal e viveram durante anos em quartéis militares, consultar Fátima Rodrigues (2017, p. 119-140)
} 
Por sua vez quanto às trajetórias deambulantes, essas correspondem aos homens cujos percursos iam errando à procura de um lugar onde sentissem que as suas opções de vida poderiam ser compreendidas e ao qual poderiam pertencer. É o caso do percurso de vida de Mário de Angola que deambulou pelo mundo desde que entrou nas FAP até estacionar em Portugal onde dizia que tinha chegado por mero acaso, e onde estava de passagem até poder voltar a partir, se possível para Angola ou então para outro país da Europa.

Mário dizia que foi recrutado à força para o serviço militar português quando já tinha passado o 25 de Abril de 1974, após ter sido apanhado em uma rusga policial na cidade de Luanda. Decorridos seis meses, Mário foi chamado para o serviço militar que começou a cumprir no dia 3 de maio de 1974, integrando as forças militares mistas que, há apenas um mês, começavam a reunir soldados portugueses e combatentes dos três movimentos de libertação, cujo objetivo era manter a ordem no território até a transferência de poderes e a retirada completa das tropas portugueses do território ${ }^{21}$. Mal as forças portuguesas saíram de Angola, Mário disse que passou para as forças do MPLA e que por isso

[...] consegui fazer duas guerras! Fiz a guerra portuguesa e fiz a guerra do MPLA. Eu como já tinha experiência da guerra portuguesa, eles me deram como instrutor. Estive no Brazaville, depois fui para o Maiongue, em Cabinda. Estive em Cabinda, então ali era instrutor (MÁRIO, informação verbal) ${ }^{22}$.

\footnotetext{
${ }^{21}$ O Artigo 32 dos Acordos de Alvor - assinados no dia 15 de Janeiro de 1975 pelo Estado Português e os movimentos de libertação nacional de Angola, que regulamentavam o processo e o calendário do acesso de Angola à independência -, determinava que as Forças Armadas dos três movimentos de libertação seriam integradas em paridade com Forças Armadas Portuguesas nas forças militares mistas em contingentes que contariam com oito mil combatentes da F.N.L.A, oito mil combatentes do M.P.L.A., oito mil combatentes da U. N. I. T. A. e 24 mil militares das Forças Armadas Portuguesas. O Artigo 33 determinava que caberia à Comissão Nacional de Defesa proceder à integração progressiva das Forças Armadas nas forças militares mistas, e que, em princípio, de Fevereiro a Maio, inclusive, seriam integrados por mês, quinhentos combatentes de cada um dos movimentos de libertação e mil e quinhentos militares portugueses e de Junho a Setembro, inclusive, seriam integrados por mês, mil e quinhentos combatentes de cada um dos movimentos de libertação e quatro mil e quinhentos militares portugueses. Além disso, acordava-se, no artigo 34, que os efetivos das Forças Armadas Portuguesas que excedessem o contingente referido no artigo anterior, deveriam ser evacuados de Angola até trinta de Abril de 1975 e que, segundo o artigo 35, a evacuação do contingente das Forças Armadas Portuguesas integrado nas forças militares mistas deveria iniciar-se a partir de um de Outubro de 1975 e ficar concluída até vinte e nove de Fevereiro de 1976 (Acordo de Alvor, Arquivo Histórico-Diplomático do Ministério dos Negócios Estrangeiros, 1316-PAA, p. 944).

${ }^{22}$ Depoimento verbal de Mário concedido à autora em entrevista em Lisboa, no dia 23 de janeiro de 2009.
}

Mário pensava que chegaria a ser oficial das Forças Armadas Angolanas, o que não veio a acontecer porque nunca chegou a ser promovido até essa patente. Desiludido, Mário ainda pensou em regressar a Cabinda para apanhar uns diamantes, o que também já não foi possível porque, segundo justificava, a área já estava totalmente controlada. Para garantir o seu futuro, Mário tirou então uma formação de marinheiro e trabalhou em um navio onde percorreu vários países do mundo, até que, devido a uns problemas legais, o navio ficou apreendido em Portugal no ano de 1991. Nessa altura as autoridades portuguesas ofereceramlhe a possibilidade de ficar em Portugal, proposta que aceitou.

Em Portugal, Mário conseguiu o seu primeiro trabalho nas obras de requalificação do Rossio e dali conseguiu outro, nas obras da Ponte Vasco da Gama, até ao dia em que sofreu um acidente de trabalho que vitimou de morte vários trabalhadores. Mário sobreviveu, mas não conseguiu mais trabalhar porque a sua saúde deixou de permitir. Os projetos que imaginava para o seu futuro não radicavam em Portugal. Todos se reportavam à Angola. Pensava retomar a atividade de artesanato que desenvolvia antes da sua breve passagem pelas FAP ou, então, ser taxista. Projetos que alimentava desde que chegara a Portugal. Projetos que desabaram no momento em que se apercebeu que um irmão seu, que encontrou em Portugal, ficou com o dinheiro que poupara e que guardava na sua conta no banco. Projetos que Mário continuava a alimentar com base na esperança de receber uma indemnização do Estado português pela sua participação na guerra ${ }^{23}$. Mário não se identificava com o passado português em Angola. O que recordava desse tempo era a brutalidade da força colonial, e a discriminação que sentia quando era proibido de entrar em determinados estabelecimentos só por ser africano. E recordava, ainda, a vida de seu pai e de seu avô que afirmava, com rancor, terem vivido explorados e morrido na miséria, como escravos, destino ao qual, desde muito novo, queria fugir. O Mário residia em Portugal por acaso, onde ia permanecendo e onde

\footnotetext{
${ }^{23}$ Desde janeiro de 2007, quando entregou o seu processo relativo à Lei 9/2002, que Mário procura que lhe seja atribuída uma reforma ou uma indemnização que, segundo a sua opinião, o Estado Português lhe deve por ter estado ao seu serviço antes da independência de Angola. Por isso, também já enviou uma carta ao Ministério da Defesa, datada de 8 de abril de 2008, onde descreve a sua situação quando passa à disponibilidade e apresenta as suas exigências. Até ao dia 2 de fevereiro de 2009, Mário só conseguiu obter uma resposta: o seu processo não existe no Arquivo Geral do Exército.
} 
alimentava a possibilidade de realizar vários projetos de vida preferencialmente em Angola, mas enquanto esses não se concretizavam imaginava outros em Portugal ou noutro qualquer país Europeu onde residiam algum dos seus familiares. O percurso do Mário era deambulante. Desde que foi recrutado para as FAP, nunca mais conseguiu encontrar um rumo para a sua vida. A sua trajetória deambulava entre possibilidades porque nunca reencontrou um lugar ao qual conseguisse pertencer.

Essa breve incursão pela tipologia de percursos de vida dos antigos combatentes africanos das FAP, ilustrada por alguns exemplos concretos de trajetórias de vida e de discursos justificativos das mesmas por parte de antigos combatentes africanos das FAP, permite mostrar como o colonialismo, a guerra e o póscolonialismo marcaram as trajetórias desses homens. Apesar de todos terem passado mais ou menos pelas mesmas ruturas e descontinuidades geradas pelas profundas transformações históricas que as suas vidas atravessaram, a análise efetuada indicou que os percursos desses homens não foram todos afetados, por esses fatores, da mesma forma. O colonialismo, a guerra e o pós-colonialismo não produziram os mesmos efeitos nos percursos de diferentes sujeitos, embora se tenha verificado que a guerra os tenha desviado a todos temporária ou definitivamente dos rumos que imaginavam e desejavam traçar para as suas vidas antes de terem sido recrutados para as FAP.

\section{Considerações finais: dos percursos desviados às identidades à deriva}

Os percursos de vida dos antigos combatentes africanos revelam uma trajetória não linear, derivada dos desvios e das interferências múltiplas e contraditórias a que foram sujeitos na África e no Portugal coloniais e pós-coloniais. É ao longo desses espaços-tempo, marcados por várias ruturas e descontinuidades, que esses homens vão encontrando uma multiplicidade de referências identitárias. Referências e pertenças que se multiplicam, sobrepõem, substituem e alternam à medida que vão ocupando diferentes posições nas diversas geografias culturais, políticas, espaciais, ideológicas e institucionais que atravessam nos seus percursos.

Assim, e independentemente da variação das suas trajetórias de vida, as identidades desses homens não podem deixar de ser múltiplas, contraditórias e variáveis, correspondendo àquelas que Stuart Hall (2006, p. 72-73; 1997, p. 9-11) considera próprias de quem foi obrigado a adotar várias posições de identificação deslocadas, posições que se configuram no seio de forças que pressionam os sujeitos em diversas direções. De fato, a vida dos antigos combatentes africanos atravessou campos cujas forças se diferenciaram entre si inconfundivelmente, obrigando-os a ocupar posições e a adotar, ou pelo menos a representar, referências identitárias controversas entre si. Cada posição que ocuparam teve lugar em um campo de forças que, longe de ser unitário e hermético, suportava relações aparentemente dicotómicas e convocava diversas temporalidades. Durante a colonização, esses homens, de origem africana, são colonizados; constituem-se na relação colonial, em uma relação assimétrica e dialógica com a alteridade. Uma relação onde se distinguem do colonizador, fundamentalmente no seio das relações de poder, mas também quanto às suas raízes, aos seus modelos culturais, onde a língua, a religião, a família, os costumes embatem com os modelos do colonizador cuja força os confronta e violenta ameaçando-os, por vezes, de dissolução. É nesse contexto que esses homens integram as FAP e onde os seus modelos identitários têm de reposicionar-se face à alteridade, em uma nova relação onde é suposto que eles se confundam com o outro colonizador. Mas, nesse novo contexto, o soldado africano não deixa de ser o colonizado, embora passe a ser o colonizado no lugar do colonizador.

As independências dos territórios africanos ${ }^{24}$, contra as quais lutaram na força colonial, deixam esses homens em uma situação mais uma vez deslocada. Os antigos combatentes africanos da força colonial não pertencem a esses territórios, pois neles a posição de colonizador, que ocuparam temporariamente, sobrepõe-se ao lugar de colonizado que nunca deixaram de ter na relação colonial. E, o Portugal que encontram, o Portugal póscolonial, menospreza a posição de antigo combatente que revindicam para nele poderem encontrar o lugar de pertença onde os seus percursos e identidades possam fazer sentido. Essas conjugações remetem, igualmente, para a problemática das identidades construídas nas fronteiras dos diversos embates culturais, ideológicos, políticos, institucionais, no seio dos quais os seus percursos se viram enredados. Identidades que, como defendem por exemplo Susan Friedman (2001) e Mary Louise Pratt (1991; 1992), se configuram nas

\footnotetext{
${ }^{24}$ Para conhecer a complexidade dos processos de descolonização e algumas das especificidades que envolveram as negociações das independências relativas à Angola, à Moçambique e à GuinéBissau consulte-se Fernando Rosas, Mário Machaqueiro e Pedro Aires de Oliveira (org.) (2015) e Miguel Bandeira Jerónimo e António Costa Pinto (org.) (2014).
} 
diversas fronteiras das suas existências e que, no caso concreto destes homens, interpelam as dicotomias entre colonizado e colonizador ou, como diria Bhabha (2005a; 2005b), representam a ambivalência e desestabilizam os discursos das relações colonial e pós-colonial.

$\mathrm{Na}$ lógica interpretativa de interseccionalidade de Gloria Anzaldúa (1997) ou de Patricia Hill Collins (2000), essas identidades correspondem à articulação e à incorporação de referências múltiplas e contraditórias. Nesse sentido, e no caso concreto dos antigos combatentes africanos das FAP, essas identidades são a incorporação dos espaços-tempo colonial e póscolonial e da ambivalência da relação colonizado/ colonizador; são a sobreposição, deslocada e em deslocamento, de múltiplas referências que decorrem de disjunturas entre espaços e tempos, onde os sujeitos se compõem e recompõem; onde as suas identidades se vão movendo e reorganizando nos interstícios das diferenças; são o resultado das descontinuidades históricas e das exclusões e integrações várias que marcaram os seus percursos.

Mas, ao mesmo tempo, o que os percursos e os discursos desses antigos combatentes sugerem é que, as suas identidades são identidades à deriva. Identidades construídas com base em percursos de vida desviados, mais ou menos à força, pela força da guerra, do colonialismo e dos tempos que se lhe seguiram. Identidades que têm dificuldade em acompanhar esses percursos e, por isso, andam à deriva entre territórios que ocuparam e ocupam, entre territórios que deixaram ou que deixaram de existir, entre territórios que encontraram e outros que reencontraram no Portugal pós-colonial. Nesse sentido, não são apenas "identidades sempre em curso" (SANTOS, 1994, p. 127-129). São identidades em curso, mas à procura de um lugar onde deixem de estar deslocadas, onde a sua existência possa recompor-se, onde possam pertencer, em suma, um lugar onde possam voltar a ser.

Deste modo, o que essas configurações identitárias propõem é que conceitos como os de hibridismo, mimética, identidades múltiplas, descentradas $\mathrm{e}$ deslocadas, normalmente teorizados em função de lugares e tempos mais ou menos estáveis, onde se confrontam realidades dicotómicas, têm dificuldade em dar conta de subjetividades cujas referências não apenas se sobrepõem nesses lugares, mas que se vão configurando, reconfigurando e sobrevivendo dentro, entre e fora de cada um dos vários modelos e espaços de referência que foram percorrendo. Aqueles conceitos servem para ter em atenção as formas de adaptação, de resistência e de cedência às invasões e violências coloniais. Mas são conceitos que dificilmente se adaptam à interpretação de identidades que perpassaram geografias físicas e simbólicas, circunstâncias históricas, e espaços e tempos descontínuos e contraditórios. São conceitos que não são suficientes para interpretar como se configuram as pertenças marcadas por ruturas e descontinuidades que irrompem os percursos de vida dos sujeitos. Mesmo as teorias que contemplam a diáspora e que supõem a análise de identidades que percorrem quadros de referência diversificados, como é o caso da proposta de Paul Gilroy (2001), acabam por situá-los em relação a dois ou três momentos e quadros de referência distintos, isto é os que representam o lugar de origem, o momento da deslocação e o lugar de chegada, sem fazerem referência à possibilidade dos sujeitos ocuparem alternadamente posições ambivalentes, mas também opostas, ao longo dessas deslocações e descentramentos.

Por isso, consideramos que o que os percursos de vida desses antigos combatentes sugerem é a necessidade de conceitualizar as identidades não apenas em curso, mas em um percurso onde se sobrepõem, se entrelaçam e se confrontam realidades múltiplas e opostas que, por vezes, vão se alternando e outras substituindo. Isto porque alguns dos contextos pelos quais vão passando significam a necessidade de o sujeito reposicionar-se perante um contexto cujas relações sociais se opõem àquelas que configuravam o contexto anteriormente ocupado. Para os sujeitos isso significa uma profunda perturbação da posição ou das posições ocupadas. Cada posição corresponde a um lugar que rompe com algumas configurações do sujeito pré-existente, que destroça algumas das suas pertenças, que implica a dissolução de certos elementos identitários para dar lugar a outros adequados aos novos contextos. Trata-se, então, de conceitualizar esses percursos tendo em consideração que atravessaram contextos que, segundo Luís Quintais (2000, p.987), "estilhaçam a suposta continuidade de uma vida, ameaçando-a de dissolução". Passar pela guerra não significou, apenas, posicionarse, ou ser-se posicionado, em um determinado lugar na relação colonial. Participar de uma guerra como combatente significou, também, passar a ter uma vida marcada pela irreversibilidade que representa essa passagem. Passagem que, segundo Luís Quintais (2000, p. 1000), estabelece o momento onde os combatentes deixaram de ser o que foram e passaram a ser o que são, sem possibilidade de regresso. A passagem pela guerra significa, assim, uma "descontinuidade 
ontológica", uma profunda transformação irreversível do ser: "Após essa mudança de substância o homem é inapelavelmente forçado a viver no passado, a viver como um prisioneiro das suas experiências, que é incapaz de transfigurar em memórias".

Ora, as vidas dos antigos combatentes africanos das FAP foram simultaneamente marcadas pelo colonialismo, pela guerra e pelas realidades póscoloniais inauguradas com o 25 de Abril, quer em África, quer em Portugal. Contextos que condicionaram as suas opções, desviaram os seus percursos e moldaram as suas identidades. De acordo com a análise que acabamos de apresentar, podemos, então, sugerir que se o colonialismo "condenou" os sujeitos (ex)colonizados à colonialidade do ser, ou seja, a uma espécie de não existência pela forma como lhe foi negando o estatuto humano, dando origem a sujeitos liminares que marcam o próprio limite do ser (MALDONADO-TORRES, 2007; QUIJANO, 2014), e se a guerra os "condenou" a uma transformação ontológica irreversível, o fim do colonialismo português na África reposicionou esses sujeitos, agora nas relações pós-coloniais, desviando novamente os seus percursos e obrigando-os a um reposicionamento identitário. Na África, a sua anterior posição no lugar do colonizador, foi responsável sobretudo pela rejeição a que foram sujeitos nos seus países de origem quando se deram as suas independências. Por isso, mas também pelas perseguições que sofreram, muitos partiram para Portugal no sentido de reorganizarem as suas vidas com base nesse lugar que tinham ocupado temporária e parcialmente na época colonial. Outros simplesmente não se identificaram com os projetos dos Estados independentes e por isso também partiram. Em Portugal encontraram uma realidade que, em termos gerais, os ignorou ou que se limitou a ir adiando a resolução dos seus processos interrompendo e adiando os projetos de vida que esses homens tinham idealizado. E, embora tenhamos identificado seis tipos de percursos de vida que se diferenciam entre si por diversos fatores, todos eles têm em comum o fato de as suas trajetórias de vida terem sido desviadas sobretudo pela guerra, mas que as realidades pós-coloniais, em Portugal e na África, ajudaram a criar.

\section{Referências}

ACORDO DE ALVOR. Coimbra: Centro de Documentação 25 de Abril, Universidade de Coimbra. Disponível em: http://www1. ci.uc.pt/cd25a/wikka.php?wakka=descon21. Acesso em: 2 maio 2009. https://doi.org/10.24849/spg.cpga.2017.01
ACORDO DE LUSACA. Centro de Documentação 25 de Abril, Universidade de Coimbra. Disponível em: http://www1.ci.uc.pt/ cd25a/wikka.php?wakka=descon06. Acesso em: 2 maio 2009.

AGUIAR, Luiz. Livro Negro da Descolonização. Lisboa: Editorial Intervenção, 1977.

ALMEIDA, João Ferreira de; PINTO, João Madureira. A Investigação nas Ciências Sociais. Lisboa: Editorial Presença, 1982.

ANZALDÚA, Gloria. La consciencia de la mestiza: towards a new consciousness. In: WARHOL, Robyn; HERNDL, Diane (eds.). Feminisms: an Anthology of Literary Theory and Criticism. New Brunswick: Rutgers University Press, 1997. p. 765-775. https://doi. org/10.1007/978-1-349-14428-0_44

BERNARDO, Manuel Amaro. Combater em Moçambique: guerra e descolonização 1964-1975. Lisboa: Prefácio, 2003.

BERNARDO, Manuel Amaro. Guerra, Paz e Fuzilamentos dos Guerreiros: Guiné 1970-1980. Lisboa: Prefácio, 2007.

BHABHA, Homi. O Local da Cultura. Tradução de Myriam Ávila et al. Belo Horizonte: Editora UFMG, 2005a.

BHABHA, Homi. A Questão Outra. In: SANCHES, Manuela (org.). Deslocalizar a "Europa": antropologia, Arte, Literatura e História na Pós-colonialidade. Lisboa: Edições Cotovia, 2005b. p. 143-166.

CAHEN, Michel. Uma boa consciência colonial ainda necessária num país europeu moderno? Arquivo. Boletim do Arquivo Histórico de Moçambique, Moçambique, n. 9, p.59-68, abril, 1991.

CERVELLÓ, Joseph Sánchez. La revolucción portuguesa y la questión colonial. In: ROSAS, Fernando (coord.). Portugal e a Transição para a Democracia (1974-1976). I Curso Livre de História Contemporânea. Lisboa: Edições Colibri, 1998. p. 77-106.

COELHO, João Paulo B. Da violência colonial ordenada à ordem pós-colonial violenta: sobre um legado das guerras coloniais nas ex-colónias portuguesas. Lusotopie, Aix-en-Provence, p. 175-193, 2003.

CORREIA, Pedro Pezarat. A participação local no desenvolvimento das campanhas. O recrutamento africano. In: MOREIRA, Adriano et al. (orgs.). Estudos sobre as Campanhas de África (19611974). S. Pedro do Estoril: Edições Atena e Instituto de Altos Estudos Militares, 2000. p. 143-153.

COLLINS, Patricia Hill. Black Feminist Thought: Knowledge, Consciousness, and the Politics of Empowerment. New York/ London: Routledge, 2000. https://doi.org/10.4324/9780203900055

DEMAZIÈRE, Didier. Typologie et description : À propos de l'intelligibilité des experiences vécues. Presses Universitaires de France, v. 4, p.333-347, 2013. Disponível em: https://www. cairn.info/revue-sociologie-2013-3-page-333.htm. https://doi. $\operatorname{org} / 10.3917 /$ socio.043.0333 
FLICK, Uwe, Métodos Qualitativos na Investigação Científica. Trad. Artur Parreira. Lisboa: Monitor, 2005.

FERRAROTTI, Franco. Sobre a autonomia do método biográfico. Sociologia: Problemas e Práticas, São Paulo, n. 9, p. 171-177, 1991.

FERRAROTTI, Franco. Historias de vida y ciencias sociales - entrevista a Franco Ferrarotti, por Monserrat Iniesta e Carles Feixa. Perifèria - Revista de Recerca i formació en antropología, n. 5, p. 1-14, 2006. Disponível em: http://www.raco.cat/index.php/ Periferia/article/viewFile/146549/198369. Acesso em: 23 mar. 2009. https://doi.org/10.5565/rev/periferia.162

FRIEDMAN, Susan Stanford. O Falar da Fronteira, o hibridismo e a performatividade: teoria da cultura e identidade nos espaços intersticiais da diferença. Revista Crítica de Ciências Sociais, Coimbra, n. 61, p. 5- 28, dez. 2001.

GILROY, Paul. O Atlântico Negro: Modernidade e Dupla Consciência. Trad. Cid Knipel Moreira. São Paulo: Ed. 34, 2001. https://doi.org/10.1590/s0034-77012002000100013

GONÇALVES, António Custódio (org.). O Islão na África Subsariana. In: ACTAS do 6을 Colóquio Internacional "Identidades, Poderes e Etnicidades. O Islão na África Subsariana". Porto: FLUP, 2004. https://doi.org/10.1787/888933228486

GUERRA, Isabel. Pesquisa Qualitativa e Análise de Conteúdo: sentidos e formas de uso. Estoril: Princípia Editora, 2006.

HALL, Stuart. Da Diáspora - Identidades e Mediações Culturais. Tradução de Adelaine Resende et al. Belo Horizonte: UFMG, 2006.

HALL, Stuart. Identidade Cultural. Tradução de Vanderli Silva. São Paulo: Fundação Memorial da América Latina, 1997.

HOOKS, Bell. Choosing the margin as a space of radical openness. In: HARDING, Sandra (ed.). The Feminist Standpoint Theory Reader: intellectual and political controversies. New York/ London: Routledge, 2004. p. 153-159.

JERÓNIMO, Miguel Bandeira; PINTO, António Costa (org.). Portugal e o Fim do Colonialismo: dimensões internacionais. Lisboa: Edições 70, 2014.

JOSSIAS, Elias. Entre a Colónia e a Nação: Moçambicanos Deficientes Físicos das Forças Armadas Portuguesas. Lisboa: ISCTE, 2007.

JOVCHELOVITCH, Sandra; BAUER, Martin W. Entrevista narrativa. In: BAUER, M. W.; GASKELL, G. (org.). Pesquisa qualitativa com texto, imagem e som: um manual prático. 10. ed. Petrópolis: Vozes, 2012. p. 90-113.

LAKATOS, Eva Maria; MARCONI, Marina Andrade. Fundamentos de Metodologia Científica. São Paulo: Atlas, 1991.

LEÃO, Ana; RUPIYA, Martin. A military history of the Angolan Armed Forces from the 1960s onwards - as told by formers combatants. In: RUPIYA, Martin (ed.). Evolutions \& Revolutions: A Contemporary History of Militaries in Southern Africa. Pretoria: Institute for the Security Studies, 2005. p. 7-41.
MALDONADO-TORRES, Nelson. Sobre la colonialidad del ser: contribuciones al desarrollo de un concepto. In: CASTROGÓMEZ, Santiago; GROSFOGUEL, Ramón (Orgs.). El giro decolonial: reflexiones para una diversidad epistémica más allá del capitalismo global. Bogotá: Universidad Javeriana-Instituto Pensar, Universidad Central-IESCO, Siglo del Hombre Editores, 2007. p. 127-167. https://doi.org/10.7440/histcrit33.2007.09

PAIS, José Machado, Sociologia da Vida Quotidiana: teorias, métodos e estudos de caso. Lisboa: Imprensa de Ciências Sociais, 2007.

PÀMPOLS, Carlos Feixa. La imaginación autobiográfica. Perifèria - Revista de recerca i formació en antropologia, n. 5, p. 1-44, 2006. Disponível em: http://revistes.uab.es/periferia/ article/viewFile/159/176. Acesso em: 28 mar. 2009. https://doi. org/10.5565/rev/periferia. 159

PORTUGAL. Estado-Maior do Exército. Resenha HistóricoMilitar das Campanhas de África, v. I. Lisboa: Comissão para o Estudo das Campanhas de África, 1988.

PRATT, Mary Louise. Arts of the Contact Zone. Profession 91, New York: Modern Language Association, 1991. p. 33-40.

QUIJANO, Anibal. Colonialidad del poder y classificación social. In: CUESTIONES y horizontes: de la dependencia histórico-estructural a la colonialidad/descolonialidad del poder. Buenos Aires: CLASCO, 2014. p.285-327. (Colección Antologías). Disponível em: http://www.lavaca.org/wp-content/ uploads/2016/04/quijano-clasificacion-social.pdf. https://doi. org/10.5195/jwsr.2000.228

QUINTAIS, Luís. Liminaridade e metamorfose: uma reflexão antropológica sobre uma desordem psiquiátrica, Análise Social, Lisboa, v. 34, n. 153, p. 985-1005, 2000.

RODRIGUES, Fátima da Cruz. A desmobilização dos antigos combatentes africanos das Forças Armadas Portuguesas. Ler História, Lisboa, v. 65, p. 113-128, 2013. https://doi.org/10.4000/ lerhistoria.484

RODRIGUES, Fátima da Cruz. Antigos Combatentes Africanos das Forças Armadas Portuguesas - A Guerra Colonial como Território de (Re)conciliação. Lisboa: Instituto Camões, 2017. https://doi.org/10.4000/lerhistoria.484

RODRIGUES, Rui. Os Últimos Guerreiros do Império. Amadora: Erasmos, 1995.

ROSAS, Fernando; MACHAQUEIRO, Mário; OLIVEIRA, Pedro Aires (org.). O Adeus ao Império: 40 anos de Descolonização Portuguesa. Lisboa: Veja, 2015.

SAID, Edward W. Cultura e Imperialismo. Trad. Denise Bottman. São Paulo: Companhia das Letras, 1995.

SANTOS, Boaventura de Sousa. Pela Mão de Alice: o social e o político na pós-modernidade. Porto: Afrontamento, 1994.

SANTOS, Boaventura de Sousa. Do pós-moderno ao pós-colonial e para além de Um e Outro. Conferência de abertura do VIII 
Congresso Luso-Afro-Brasileiro de Ciências Sociais, Coimbra, 2004. https://doi.org/10.12702/viii.simposfloresta.2014.66-570-1

SCHÜTZE, Fritz. Pesquisa biográfica e entrevista narrativa. In: WELLER, W.; PFAFF, N. (org.). Metodologias da pesquisa qualitativa em educação: teoria e prática. 2. ed. Petrópolis: Vozes, 2011. p. 210-222.

SPIVAK, Gayatari Chakravorty. Can the subaltern speak? In: NELSON, C.; GROSSBERG, L. (org.). Marxism and the Interpretation of Culture. Londres: Macmillan, 1988. p. 66-111.

Recebido em: 31/10/2018.

Aprovado em: 2/4/2019.

Publicado em: 5/7/2019.

\section{Autora/Author:}

FÁtima DA CRUZ Rodrigues fatimadacruzrodrigues@gmail.com

- Doutora em Sociologia pela Universidade de Coimbra, docente da Universidade Lusíada e professora convidada na Faculdade de Direito da Universidade do Porto. Atualmente, é investigadora no Centro de Estudos Sociais da Universidade de Coimbra no âmbito do projeto internacional "MEMOIRS - Filhos de Império e Pós-memórias Europeias" (ERC Consolidator Grant, $n^{\circ}$ 648624)

Grant, no 648624).

- PhD in Sociology from the University of Coimbra, lecturer at the Lusíada University of Porto and visiting lecturer at the Faculty of Law of the University of Porto. Researcher at the Centre for Social Studies, University of Coimbra in the project "MEMOIRS - Childs of Empire", funded by the European Research Council (ERC) under the European Union's Horizon 2020 research and innovation programme (grant agreement No. 648624).

- Doctorada en Sociología por la Universidad de Coimbra, profesora de la Universidad Lusíada y profesora invitada en la Facultad de Derecho de la Universidad de Oporto. Investigadora en el Centro de Estudios Sociales de la Universidad de Coimbra en el proyecto internacional "MEMOIRS - Hijos de Imperio y Post-memorias europeas" (ERC Consolidator Grant, no 648624). 